\title{
SIZE EFFECT OF PLAIN CONCRETE BEAMS-AN EXPERIMENTAL STUDY
}

\author{
T. Muralidhara Rao ${ }^{1}$, T.D.Gunneswara Rao ${ }^{2}$ \\ ${ }^{1}$ Dept.of Civil Engg., Vardhaman College of Engg., Hyderabad-501218. A.P., India.09989214274 \\ ${ }^{2}$ Dept of Civil Engg, NIT Warangal506004. A.P, India,09912995173,tmuralidhararao@gmail.com,tdgtdg@gmail.com
}

\begin{abstract}
The paper analyses the size dependency of the fracture energy $\left(G_{F}\right)$ and the effective length of fracture process zone $\left(C_{f}\right)$ of concrete determined as per the Bazant's Size effect method and RILEM Work-of-fracture methods. The fracture parameters $\left(G_{F}, C_{f}\right)$ are determined by measuring the maximum loads of geometrically similar notched plain concrete (M25) specimens of different sizes in a size ratio of 1:5 with different pre-cast notch depths $(a / d=0.15,0.30$ and 0.45$)$ under three point bending through load-deflection curves. In each notch depth ratio, 15 beams are cast and tested with 03 similar specimens in each size of the beams. Total beams tested are 45.The variation of both the fracture energy and the effective length of fracture process zone as a function of the specimen size and notch depth is determined using Bazant's Size effect method and RILEM Work-of-fracture method. Fracture energy and Fracture process zone length determined by Size effect method are found to be decreasing with the increasing notch depth ratios. Fracture energy calculated using Work-of-fracture method is increasing with the increase in size of specimen and decreasing with the increasing notch depth ratios.
\end{abstract}

Keywords: Brittleness number, Characteristic size, Crack length, Effective length of fracture process of zone, Fracture parameters, Fracture energy, Notch-depth ratio, Size effect.

\section{INTRODUCTION}

The size effect on structural strength is an important phenomenon with a very old history. Unfortunately, despite abundant experimental evidence, this phenomenon is still not taken into account in most specifications of the design codes for concrete structures, as well as the design practices.

Generally, concrete structures are designed based on the strength of a standard specimen size. The actual concrete strength of relatively larger structural members may be significantly lower than that of the standard size. In fact, with the increasing size of the specimens, the failure load increases but the nominal stress decreases. By neglecting size effect, predicted load capacity values are less conservative as the member size increases. The size effect can be quantified by comparing the stress at the maximum load of geometrically similar specimens of different sizes with geometrically similar notch ratios.

\section{SIZE EFFECT METHOD}

Bazant [1] proposed the size dependency of nominal strength of geometrically similar concrete structures by the size effect law. Fig 1 shows a typical three point bend test set up for the determination of fracture parameters using Size effect method [2].
****

$$
\sigma_{N=} \frac{B f_{t}}{\sqrt{1+\beta}}, \quad \beta=\frac{d}{d_{o}}
$$

Where $\mathrm{ft}$ is the material tensile strength, $\beta$ is the brittleness number, and $\mathrm{B}$ and $\mathrm{d} 0$ are empirical constants. The nominal strength of two-dimensional similar structures is defined as

$$
\sigma_{N=} c_{n} \frac{P_{u}}{b d}
$$

Where $\mathrm{cn}$ is a coefficient introduced for convenience, $\mathrm{Pu}$ is the ultimate load, $b$ is the specimen thickness, and $d$ is the characteristic specimen size (i.e., height of the beam). When $\beta$ is very small (e.g., <0.1), the behavior of a structure is more ductile and the nominal strength of the structure approaches the plastic or yield limit. But when $b$ is very large (e.g., >10), the behavior tends to be more brittle and the nominal strength approaches the prediction by linear elastic fracture mechanics (LEFM) [1].

To facilitate the evaluation of the constants in the size effect law, the above equation can be written as 


$$
\left(\frac{1}{\sigma_{N}}\right)^{2}=\left[\frac{1}{\left(B f_{t}\right)^{2} d_{o}}\right] d+\left[\frac{1}{\left(B f_{t}\right)}\right]^{2}
$$

If the experimental data are arranged in a plot of $\mathrm{X}=\mathrm{d}$ and $\mathrm{Y}$ $=\left(\frac{1}{\sigma_{N}}\right)^{2}$ $=\left(\sigma_{N}\right) ;$ a linear regression equation may be found as $\mathrm{Y}$ $=\mathrm{AX}+\mathrm{C}$. Then $\mathrm{B}$ and do can be evaluated from $\mathrm{A}$ and $\mathrm{C}$ as

$$
B f_{t}=\frac{1}{\sqrt{C}} \quad ; \quad d_{o=}\left(\frac{C}{A}\right)
$$

Size Effect Method -RILEM Recommendations [2] for Fracture energy (Gf)and Effective length of Process zone length $(\mathrm{Cf})$

The procedure for determining the fracture parameters using size effect method consists of testing the geometrically similar specimens under three point loading as shown in Fig.1. A correction for the load carrying capacity of the specimen is required to consider the influence of self-weight of the member.

a) The corrected maximum loads $P_{1}^{o}, \ldots \ldots \ldots \ldots \ldots . . . . ., P_{n}^{o}$ which take the weight of the Specimens into account, have to be calculated. If $\mathrm{lj}$ is almost the same as $\mathrm{Sj}$,

$$
P_{1}^{o}=P_{j}+\frac{1}{2} m_{j} g \quad(\mathrm{j}=1,2 \ldots \mathrm{n})
$$

Where $\mathrm{mj}$ is the mass of specimen $\mathrm{j}, \mathrm{g}=$ acceleration due to gravity, and $\mathrm{n}=$ number of tests conducted.

b) Linear regression can be carried out by taking the ordinates of $\mathrm{Yj}$ on $\mathrm{Y}$-axis the ordinates of $\mathrm{Xj}$ on $\mathrm{X}$-axis

Where $Y_{j}=\left(\frac{b d_{j}}{P_{j}^{o}}\right)^{2} ; \quad \mathrm{Xj}=\mathrm{dj}$

c) The slope and intercept of the regression line $\mathrm{Y}=\mathrm{AX}+\mathrm{C}$ can be calculated using the following expressions.

$$
\frac{\sum_{j}\left(X_{j}-\bar{X}\right)\left(Y_{j}-\bar{Y}\right)}{\sum_{j}\left(X_{j}-\bar{X}\right)^{2}}
$$

$$
\begin{array}{r}
\text { Intercept, } \mathrm{C}=\bar{Y}-A \bar{X} \\
\text { Where } \bar{X}=\frac{1}{n} \sum_{j} X_{j}, \quad, \quad=\frac{1}{n} \sum_{j} Y_{j}
\end{array}
$$

Where $(\bar{X}, \bar{Y})=$ centroid of the data points. The plot of data points is to be checked for linearity. If it is not linear, then some errors or disturbing effects have probably occurred in the test procedure.

d) The auxiliary values for the extrapolation are to be calculated to very large specimen sizes for which linear elastic fracture mechanics applies. For known values of relative crack

length, $\alpha=\frac{a}{d}$, where $\alpha=$ crack length,

For $\mathrm{S} / \mathrm{d}=2.5$

$$
F_{2.5}(\alpha)=\frac{1.0-2.5 \alpha+4.49 \alpha^{2}-3.98 \alpha^{3}+1.33 \alpha^{4}}{(1-\alpha) 3 / 2}
$$

For $\mathrm{S} / \mathrm{d}=4$

$$
F_{4}(\alpha)=\frac{1.99-\alpha(1-\alpha)\left(2.15-3.93 \alpha+2.7 \alpha^{2}\right)}{\pi \frac{1}{2}(1+2 \alpha)(1-\alpha) 3 / 2}
$$

For $\mathrm{S} / \mathrm{d}=8$

$$
F_{8}(\alpha)=1.11-2.12 \alpha+7.71 \alpha^{2}-13.55 \alpha^{3}+14.25 \alpha^{4}
$$

Linear interpolation can be used for other values of s/d For example,

For $4<\mathrm{S} / \mathrm{d}<10$

$$
F(\alpha)=F_{4}(\alpha)+\frac{[(S / d)-4]}{4}\left[F_{8}(\alpha)-F_{4}(\alpha)\right]
$$

The non-dimensional energy release rate is

$$
g(\alpha)=\left(\frac{S}{d}\right)^{2} \pi \alpha[1.5 F(\alpha)]^{2}
$$

For $\alpha \mathrm{o}=a_{o} / \mathrm{d}, \mathrm{g}(\alpha=\alpha \mathrm{o})$ is to be calculated.

e) Now, the fracture energy Gf (mean prediction) can be calculated using the following expression: 


$$
G_{f}=\frac{g\left(\alpha_{o}\right)}{E_{c} A}
$$

\subsection{Fracture Process Zone Length}

The size-effect method makes it also possible to determine the effective length $\mathrm{Cf}$ of the fracture process zone. This fracture parameter represents the length of the equivalent linear elastic crack that gives the same unloading compliance as the actual crack in an infinitely large specimen at the peak load.

$$
C_{f=} \frac{g\left(\alpha_{o}\right)}{g^{\prime}\left(\alpha_{o}\right)} d_{o}=\frac{g\left(\alpha_{o}\right)}{g^{\prime}\left(\alpha_{o}\right)}\left(\frac{C}{A}\right)
$$

Where $g^{\prime}\left(\alpha_{o}\right)_{=}^{\frac{d g\left(\alpha_{o}\right)}{d \alpha_{o}}}$

\section{WORK-OF-METHOD [3]}

Based on a measured load-deflection curve of a fracture specimen, typically a three point bend beam, the work of load $\mathrm{P}$ (including the effect of its own weight) on the load-point displacement $\delta$ in RILEM method is calculated as

$$
W_{f}=\int P d \delta
$$

The fracture energy according to the RILEM definition,

$$
G_{f}\left(\alpha_{o}, d\right)=\frac{W_{f}}{B\left[\left(1-\alpha_{o}\right) d\right]} \quad \alpha_{o}=\left(\frac{a_{o}}{d}\right)
$$

Zdenek.P.Bazant and Mohammad.T.Kazemi [3] concluded that fracture energy determined based on work-of-fracture method is size dependent, though the RILEM recommendations say that the work-of-fracture method is size independent. Further, it was mentioned in three point bent fracture specimens, the fracture energy according to the RILEM definition is dependent on the notch depth also.

Sidney [4] Mindess concluded that the fracture energy (GF) and Fracture toughness (KIC) increased considerably for the largest beams tested. The largest beam size tested was 400mmx400mmx3360mm.

W.Brameshuber and H.K.Hilsdorf [5] found an increase of fracture energy of about 20 percent when the beam depth was increased from $100 \mathrm{~mm}$ to $800 \mathrm{~mm}$.

F.H.Wittmann, H.Mihashi and N.Nomura [6] showed that the fracture energy (GF) is influenced by various factors such as the specimen size and the mix proportions. The strain softening diagram was also analyzed and the possible mechanism of size effect on fracture energy of concrete is discussed.

\section{EXPERIMENTAL PROGRAM}

\section{(i) Material Details}

Cement conforming to ASTM C150 Type I with specific gravity 3.15 is used for the concrete mix. Natural river sand with specific gravity 2.60 meeting the requirements of ASTM C-33 is used as fine aggregate. Crushed coarse aggregate passing $4.75 \mathrm{~mm}$ sieve and retained on $2.36 \mathrm{~mm}$ sieve with specific gravity 2.78 is used. The maximum aggregate size used in the study is $4 \mathrm{~mm}$. The maximum size of the coarse aggregate is limited to $4 \mathrm{~mm}$, as the smallest size of the set of beams tested was $33 \mathrm{~mm}$ (Crack free depth of a beam of height $60 \mathrm{~mm}$ with notch ratio of 0.45 ). Potable water is used for casting.

\section{(ii) Casting}

Cubes of $150 \mathrm{~mm}$ size are used to determine the compressive strength of concrete. Cylinders with $150 \mathrm{~mm}$ diameter and 300 $\mathrm{mm}$ length are used to determine the Modulus of Elasticity of concrete. Prisms of $100 \mathrm{~mm} \times 100 \mathrm{~mm} \times 400 \mathrm{~mm}$ (B x D x L) size are adopted to determine the modulus of rupture. Moulds of different dimensions are used for beams of different sizes. A needle vibrator is used for compaction. The moulds are tightly fit and all the joints are sealed by plaster of Paris in order to prevent leakage of cement slurry through the joints. The inner side of the moulds is thoroughly applied with oil.

For all notched specimens, notch plates (mild steel) of $2 \mathrm{~mm}$ thickness are used to make different notch depths at the centre of each beam. The mix proportions are thoroughly mixed in a concrete miller and the thoroughly mixed concrete is placed in the moulds and compacted using needle vibrator and the top surface is leveled with a trowel. The details of mix proportions are listed in Table 1.All the specimens are cured for 28 days in the curing tank. On 29th day, they are removed from the curing tank and the specimens are allowed to dry for 04 hours before testing. The experimental program is designed to study the variation of fracture energy and the effective length of fracture process zone of plain concrete beams under threepoint bending. Geometrically similar plain concrete beams (M25) of different sizes with varying notch depth ratios are cast.

Notch ratios of $0.15,0.30$ and 0.45 are used for the beams. Beams are cast in three batches i.e., 15 beams in each batch $(\mathrm{a} 0 / \mathrm{d}=0.15,0.30$ and 0.45$)$. Three similar beams are cast in each beam size. Along with each batch of beams, 3 cubes, 3 cylinders and 3 prisms were also cast for the determination of material properties compressive strength, Young's modulus 
and modulus of rupture respectively. The details of strength properties of concrete are summarized in Table 2.

\section{(iii) Test Results}

The cured specimens were mounted on the Tinious Olsen Universal Testing Machine (TOTM) and tested until failure. A dial gauge with least count of $0.01 \mathrm{~mm}$ is used to measure the deflection under the central load point. The capacity of Tinious Olsen Universal Testing Machine is $1780 \mathrm{kN}$. The axis of the specimen is carefully aligned at the center of the loading frame. For determining the fracture parameters with the help of size effect method, regression plots were prepared and were presented in Table3, Fig.2. The regression plots

consisted $\frac{1}{\left(\frac{P^{0}}{b d}\right)^{2}}$

on $\mathrm{Y}$-axis and size (d) on $\mathrm{X}$-axis. The regression equation is presented in the form of $Y=A X+C$.

The characteristic size of the tested beams is reported as $d_{0}=\frac{C}{A}$ and the numerator in size effect law $B f_{t}=\frac{1}{\sqrt{C}}$. Size effect plots were prepared on logarithmic scale and were presented in Fig.3 (for A, B and C series). Data pertaining to the size effect law variations is presented in Table. 4 for all series of beams tested in this investigation. From the size effect method, the fracture parameters viz., fracture energy and effective length of fracture process zone were determined and reported in Table 5. From the load deflection response of the tested specimens fracture energy was calculated using work of fracture method. The test results are tabulated in Table.6. All the tested beams (Series A, Series B and Series C) are given in Fig 6.

\section{DISCUSSION}

The fracture energy determined by the size effect method is the mean prediction for a particular notch depth ratio. From equation (1), it can be observed that for a given notched beam $\frac{g\left(\alpha_{o}\right)}{E_{c}}$ the slope of the regression line (A). The fracture energy is inversely proportional to the slope of the regression line. In the present investigation, it is found that the slope of the regression line (A) is increased with the increase in the notch depth ratio. It indicates that the increase in notch depth ratio decreases the fracture energy. In other words, increase in crack length of a structure requires less fracture energy for extending the crack (vide Fig.4). A decrease in fracture energy for crack extension indicates the brittleness of the structure. Thus it can be concluded that a crack present in a structure pushes the structure to fail in a brittle manner when the crack length (may be referred as critical crack length) approaches a particular value. From Table 5 and Fig.5, it is clear that the effective length of fracture process zone $\mathrm{Cf}$ decreased with the notch depth ratio. A higher fracture process zone indicates a ductile failure in a structure allowing more dissipation of energy through FPZ. A small FPZ indicates a brittle failure. Thus with the increase in the notch depth ratio or increase in crack length reduces the FPZ, thereby pushing the structure into a brittle failure state.

The Size effect law (SEL) graphs shown in Fig 3 represent a gradual transition from the strength criterion $\left(\sigma_{N}=B f_{t}\right.$ i.e., $\frac{d}{d_{0}}<<1$ ) to the energy criterion of LEFM ( $\frac{d}{d_{0}}>>1$ ). Size effect plots were prepared for the tested beams with varying notch depth ratio. The size effect plot was presented in Fig.3. From this plot it can further be said that the increase in

the notch depth ratio increases the $\frac{d}{d_{0}}$, making the structure fail by brittle manner wherein energy criterion of failure can be applied.

\subsection{Brittleness number}

The Brittleness number as indicated by $\beta=\frac{d}{d_{0}}$ characterizes the brittleness of the member. Quasi-brittle structures [7] are those for which $0.1 \leq \beta \leq 10$. If $\beta<0.1$, then the failure may be analyzed on the basis of the strength criterion and if $\beta>10$, then the failure may be analyzed according to the Linear Elastic Fracture Mechanics [8]. For $0.1<\beta\langle 10$, the nonlinear fracture mechanics should be used [9]. From Table 5 , it is clear that the increase in the notch ratio decreases the characteristic dimension do thereby increasing the brittleness of the member. In other words, it can be stated that an increase in the crack length (due to external forces) increases the brittle number of the element. Thus brittleness of concrete depends more on the crack size or crack length.

Table 6 shows that the fracture energy (GF) varied with the size of the specimen and the notch ratio $\alpha=(\mathrm{ao} / \mathrm{d})$. Fracture energy, GF decreased with the increased notch depth ao and increased with the increased size of the specimen (d) and hence this fracture energy is not size independent. However, it has been stated that the application of the boundary effect concept to the test results of GF indeed gives a specific fracture energy value GF that is independent of the size and shape of the test specimen [10]. The fracture energy (GF) obtained by Work-of-fracture method and the size effect was found to be varying as confirmed by Bazant and BecqGiraudon [11]. The ratio of fracture energy (GF) calculated 
using RILEM Work-of-fracture method and that of fracture energy (Gf) calculated using Size effect method is found to be more than 2.0 in case of beam series A and series B and 1.98 in case of beam series $\mathrm{C}$ respectively. The details of (GF/Gf) ratios are given in Table 7 . Size effect method (SEM) is simpler and needs less sophisticated equipment. Where as work-of-fracture method needs more sophisticated equipment and is tedious. It is observed that the fracture energy obtained from both these methods is size dependent. Thus Size effect method (SEM) is more suitable than work-of-fracture method for estimating the fracture energy, due to the simplicity of the test procedure. More tests are needed in this direction (comparing SEM and Work of fracture method) to verify the size dependency of fracture energy using highly brittle concrete (very high strength concrete) as well as highly ductile concrete (SIFCON). Till today, there is a suspicion that the difference between the two methods in estimating the fracture energy might be due to some innate fault of one or other method [12]. In these circumstances, it is convenient to assess the fracture energy parameters through SEM and can be modified by a suitable factor, if work-of-fracture method is proved to be a correct one.

\section{CONCLUSIONS}

Based on the tests on notched concrete members of different sizes and notch ratios, the following conclusions were drawn.

1. Increase in the notch ratio $(\mathrm{a} / \mathrm{d})$ increases the brittleness of the member, in other words, increase in crack length in a structure pushes the structure to behave in a brittle manner.

2. Effective length of fracture process zone $\left(\mathrm{C}_{\mathrm{f}}\right)$ decreases with the increase in the size of the member.

3. The fracture energy $\left(\mathrm{G}_{\mathrm{F}}\right)$ obtained based on work-offracture method is nearly twice the fracture energy $\left(\mathrm{G}_{\mathrm{f}}\right)$ obtained based on Size effect method (SEM).

\section{REFERENCES}

[1]. F.P. Zhou, R.V. Balendran, and A.P. Jeary, Size effect on flexural, splitting tensile and Torsional strengths of High Strength concrete, Cement and Concrete Research, Vol.28, No.12, pp.1725-1736, 1998.

[2]. Size-effect method for determining fracture energy and process zone size of concrete: RILEM DRAFT RECOMMENDATIONS, Materials and Structures, 23, 461465.

[3]. Zdenek P.Bazant and Mohammad T.Kazemi, Size dependence of concrete fracture energy determined by RILEM Work of fracture method, International Journal of Fracture 51: 121-138, 1991.

[4]. Sidney Mindess, The effect of specimen size on the fracture energy of concrete, Cement and Concrete Research, Vol. 14, Issue 3, May1984, pp. 431-436.
[5]. W.Brameshuber and H.K.Hilsdorf, Influence of ligament length and stress state on fracture energy of concrete, Engineering Fracture Mechanics, Vol.35, Issues 1-3, 1990, pp.95-106.

[6]. F.H.Wittmann, H.Mihashi and N.Nomura, Size effect on fracture energy of concrete, Engineering Fracture Mechanics, Vol.35, Issues 1-3, 1990, pp.107-115.

[7]. RILEM TC QFS Quasi-brittle fracture scaling and size effect- Final report, Materials and Structures, Vol.37, October 2004, pp 547-568.

[8]. Z.P.Bazant and M.T.Kazemi, Determination of fracture energy, process zone length and brittleness number from size effect with application to rock and Concrete, International Journal of fracture 44:1990.

[9]. Ricardo A.Einsfeld, Marta S.L.Velasco, Fracture parameters of high performance Concrete, Cement and Concrete Research, 36 (2006) 576 - 583.

[10]. Kai Duan, Xiaozhi Hu, Folker H. Wittmann, Size effect on specific fracture energy of concrete, Engineering Fracture Mechanics, 74 (2007) 87-96.

[11]. Zdenek P.Bazant, Emilie Becq-Giraudon, Statistical prediction of fracture parameters of concrete and implications for choice of testing standard, Cement and Concrete Research, 32 (2002) 529-556.

[12]. Zdenek P.Bazant, Analysis of work of fracture method for measuring fracture energy of concrete, Journal of Engineering Mechanics, Vol.122, No.2, February 1996. 
Table-1: Details of Mix Proportions and Beams

\begin{tabular}{|c|c|c|c|c|c|c|c|c|}
\hline \multirow[t]{2}{*}{$\begin{array}{l}\text { Beam } \\
\text { Series }\end{array}$} & \multirow[t]{2}{*}{$\begin{array}{l}\text { Grade of } \\
\text { Concrete }\end{array}$} & \multirow{2}{*}{$\begin{array}{l}\text { Notch } \\
\text { depth } \\
\text { ratio }\end{array}$} & \multicolumn{4}{|c|}{$\begin{array}{l}\text { Mix Proportions (Kgs per cubic meter of } \\
\text { concrete) }\end{array}$} & \multirow{2}{*}{$\begin{array}{l}\begin{array}{l}\text { Dimensions of } \\
\text { beam Specimens } \\
(1 \times b \times d)\end{array} \\
\mathrm{mm} \times \mathrm{mm} \times \mathrm{mm}\end{array}$} & \multirow[t]{2}{*}{ Designation } \\
\hline & & & Cement & $\begin{array}{l}\text { Fine } \\
\text { Aggregate }\end{array}$ & $\begin{array}{l}\text { Coarse } \\
\text { Aggregate }\end{array}$ & water & & \\
\hline \multirow[t]{5}{*}{ Series A } & M25 & 0.15 & 460 & 707.397 & 884.549 & 207 & $360 \times 80 \times 60$ & $\mathrm{~N} / 60 / 0.15$ \\
\hline & M25 & 0.15 & 460 & 707.397 & 884.549 & 207 & $540 \times 80 \times 90$ & $\mathrm{~N} / 90 / 0.15$ \\
\hline & M25 & 0.15 & 460 & 707.397 & 884.549 & 207 & $810 \times 80 \times 135$ & $\mathrm{~N} / 135 / 0.15$ \\
\hline & M25 & 0.15 & 460 & 707.397 & 884.549 & 207 & $1215 \times 80 \times 202.5$ & $\mathrm{~N} / 202.5 / 0.15$ \\
\hline & M25 & 0.15 & 460 & 707.397 & 884.549 & 207 & $1822.5 \times 80 \times 303.75$ & $\mathrm{~N} / 303.75 / 0.15$ \\
\hline \multirow[t]{5}{*}{ Series B } & M25 & 0.30 & 460 & 707.397 & 884.549 & 207 & $360 \times 80 \times 60$ & $\mathrm{~N} / 60 / 0.30$ \\
\hline & M25 & 0.30 & 460 & 707.397 & 884.549 & 207 & $540 \times 80 \times 90$ & $\mathrm{~N} / 90 / 0.30$ \\
\hline & M25 & 0.30 & 460 & 707.397 & 884.549 & 207 & $810 \times 80 \times 135$ & $\mathrm{~N} / 135 / 0.30$ \\
\hline & M25 & 0.30 & 460 & 707.397 & 884.549 & 207 & $1215 \times 80 \times 202.5$ & $\mathrm{~N} / 202.5 / 0.30$ \\
\hline & M25 & 0.30 & 460 & 707.397 & 884.549 & 207 & $1822.5 \times 80 \times 303.75$ & $\mathrm{~N} / 303.75 / 0.30$ \\
\hline \multirow[t]{5}{*}{ Series C } & M25 & 0.45 & 460 & 707.397 & 884.549 & 207 & $360 \times 80 \times 60$ & $\mathrm{~N} / 60 / 0.45$ \\
\hline & M25 & 0.45 & 460 & 707.397 & 884.549 & 207 & $540 \times 80 \times 90$ & $\mathrm{~N} / 90 / 0.45$ \\
\hline & M25 & 0.45 & 460 & 707.397 & 884.549 & 207 & $810 \times 80 \times 135$ & $\mathrm{~N} / 135 / 0.45$ \\
\hline & M25 & 0.45 & 460 & 707.397 & 884.549 & 207 & $1215 \times 80 \times 202.5$ & $\mathrm{~N} / 202.5 / 0.45$ \\
\hline & M25 & 0.45 & 460 & 707.397 & 884.549 & 207 & $1822.5 \times 80 \times 303.75$ & $\mathrm{~N} / 303.75 / 0.45$ \\
\hline
\end{tabular}

Table-2: Mechanical Properties

\begin{tabular}{|l|l|l|l|l|}
\hline $\begin{array}{l}\text { Beam } \\
\text { Series }\end{array}$ & $\begin{array}{l}\text { Wet density } \\
\left(\mathrm{kN} / \mathrm{m}^{3}\right)\end{array}$ & $\begin{array}{l}\text { Cube } \\
\text { Compressive } \\
\text { strength (fck) } \\
\mathrm{MPa}\end{array}$ & $\begin{array}{l}\text { Modulus of rupture on } \\
\text { Prisms (fbt) MPa }\end{array}$ & $\begin{array}{l}\text { Modulus of Elasticity (E) } \\
\text { Mpa }\end{array}$ \\
\hline Series A & 24.067 & 33.185 & 3.603 & 25153.333 \\
\hline Series B & 23.563 & 40.444 & 4.242 & 27527.500 \\
\hline Series C & 24.067 & 26.815 & 3.869 & 28289.000 \\
\hline
\end{tabular}

Table-3: Linear Regression Data \& Corresponding Graphs

\begin{tabular}{|c|c|c|c|c|c|c|c|c|c|}
\hline \multirow[b]{2}{*}{$\begin{array}{l}\text { Beam } \\
\text { Size }(\mathrm{d}) \\
(\mathrm{mm})\end{array}$} & \multicolumn{3}{|c|}{ SERIES A } & \multicolumn{3}{|c|}{ SERIES B } & \multicolumn{3}{|c|}{ SERIES C } \\
\hline & $\begin{array}{l}\mathrm{Y}= \\
(\mathrm{bd} / \mathrm{po})^{2} \\
\mathrm{MPa}^{-2}\end{array}$ & $\begin{array}{l}\mathrm{Y}= \\
(\mathrm{bd} / \mathrm{po})^{2} \\
\mathrm{MPa}^{-2}\end{array}$ & $\begin{array}{l}\mathrm{Y}= \\
(\mathrm{bd} / \mathrm{po})^{2} \\
\mathrm{MPa}^{-2}\end{array}$ & $\begin{array}{l}\mathrm{Y}= \\
(\mathrm{bd} / \mathrm{po})^{2} \\
\mathrm{MPa}^{-2}\end{array}$ & $\begin{array}{l}\mathrm{Y}= \\
(\mathrm{bd} / \mathrm{po})^{2} \\
\mathrm{MPa}^{-2}\end{array}$ & $\begin{array}{l}\mathrm{Y}= \\
(\mathrm{bd} / \mathrm{po})^{2} \\
\mathrm{MPa}^{-2}\end{array}$ & $\begin{array}{l}\mathrm{Y}= \\
(\mathrm{bd} / \mathrm{po})^{2} \\
\mathrm{MPa}^{-2}\end{array}$ & $\begin{array}{l}\mathrm{Y}= \\
(\mathrm{bd} / \mathrm{po}) \\
\mathrm{MPa}^{-2}\end{array}$ & $\begin{array}{l}\mathrm{Y}= \\
(\mathrm{bd} / \mathrm{po}) \\
\mathrm{MPa}^{-2}\end{array}$ \\
\hline 60 & 4.29 & 4.19 & 4.39 & 7.41 & 8.73 & 8.73 & 16.47 & 15.73 & 14.38 \\
\hline 90 & 4.81 & 4.97 & 5.06 & 8.62 & 8.06 & 8.24 & 21.08 & 20.35 & 19.01 \\
\hline 135 & 5.54 & 5.68 & 6.12 & 9.64 & 9.34 & 8.27 & 24.54 & 22.78 & 26.54 \\
\hline 202.5 & 6.86 & 6.39 & 7.11 & 12.39 & 13.67 & 12.85 & 30.2 & 28.57 & 29.64 \\
\hline 303.75 & 7.81 & 7.67 & 7.57 & 13.64 & 13.75 & 16.89 & 37.08 & 37.59 & 37.59 \\
\hline
\end{tabular}


Table-4: Size Effect Law Data \& Corresponding Graphs

\begin{tabular}{|l|l|l|l|l|l|l|}
\hline $\begin{array}{l}\text { Depth } \\
\text { of } \\
\text { beam }\end{array}$ & \multicolumn{2}{|l|}{} & \multicolumn{2}{l|}{} & \multicolumn{2}{l|}{} \\
\hline & SERIES A & \multicolumn{2}{l|}{ SERIES B } & & \multicolumn{2}{l|}{ SERIES C } \\
$\mathrm{mm}$ & $\log \left(\mathrm{d} / \mathrm{d}_{\mathrm{o}}\right)$ & $\log \left(\sigma_{\mathrm{N}} / \mathrm{Bf}_{\mathrm{t}}\right)$ & $\log \left(\mathrm{d} / \mathrm{d}_{\mathrm{o}}\right)$ & $\log \left(\sigma_{\mathrm{N}} / \mathrm{Bf}_{\mathrm{t}}\right)$ & $\log \left(\mathrm{d} / \mathrm{d}_{\mathrm{o}}\right)$ & $\log \left(\sigma_{\mathrm{N}} / \mathrm{Bf}_{\mathrm{t}}\right)$ \\
\hline 60 & -0.652 & -0.044 & -0.628 & -0.046 & -0.358 & -0.079 \\
\hline 90 & -0.475 & -0.063 & -0.452 & -0.066 & -0.182 & -0.109 \\
\hline 135 & -0.299 & -0.088 & -0.276 & -0.092 & -0.0056 & -0.149 \\
\hline 202.5 & -0.123 & -0.122 & -0.099 & -0.127 & 0.17 & -0.197 \\
\hline 303.75 & 0.053 & -0.164 & 0.076 & -0.17 & 0.347 & -0.254 \\
\hline
\end{tabular}

Table-5: Fracture Parameters From Size Effect Method

\begin{tabular}{|l|l|l|l|l|l|l|l|}
\hline $\begin{array}{l}\text { Beam } \\
\text { series }\end{array}$ & $\begin{array}{l}\mathrm{A} \\
\left(\mathrm{mm}^{-1} \mathrm{MPa}^{-2}\right)\end{array}$ & $\mathrm{C}\left(\mathrm{MPa}^{-2}\right)$ & $\mathrm{d}_{\mathrm{o}}(\mathrm{mm})$ & $\begin{array}{l}\mathrm{B} \mathrm{ft} \\
\mathrm{MPa}\end{array}$ & $\begin{array}{l}\text { Fracture energy } \\
\left(\mathrm{a}_{\mathrm{o}} / \mathrm{d}\right)\end{array}$ & $\begin{array}{l}\text { Eean prediction }) \\
\left(\mathrm{G}_{\mathrm{f}}\right) \mathrm{N} . \mathrm{m} / \mathrm{m}^{2} .\end{array}$ & $\begin{array}{l}\text { FPZ length of } \\
(\text { Mean prediction }) \\
\left(\mathrm{C}_{\mathrm{f}}\right) \mathrm{mm} .\end{array}$ \\
\hline Series A & 0.0138 & 3.7114 & 268.942 & 0.519 & 0.15 & 59.17 & 60.99 \\
\hline Series B & 0.0297 & 5.9780 & 201.283 & 0.409 & 0.30 & 49.11 & 50.27 \\
\hline Series C & 0.0862 & 11.788 & 136.752 & 0.291 & 0.45 & 43.50 & 34.66 \\
\hline
\end{tabular}

Table-6: Fracture Energy From Work Of Fracture Method

\begin{tabular}{|l|l|l|l|}
\hline \multirow{2}{*}{ Size of beam $(\mathrm{d})$} & \multicolumn{3}{|l|}{ Fracture energy, $\mathrm{G}_{\mathrm{F}}$} \\
\hline \multirow{4}{*}{$\mathrm{mm}$} & $\left(\mathrm{N}-\mathrm{m} / \mathrm{m}^{2}\right)$ & \multicolumn{2}{l|}{} \\
\cline { 2 - 4 } & Series A & Series B & Series C \\
\hline 60 & 75.62 & 55.61 & 41.86 \\
\hline 90 & 102.13 & 83.87 & 57.51 \\
\hline 135 & 130.69 & 109.26 & 86.99 \\
\hline 202.5 & 159.05 & 126.46 & 106.7 \\
\hline 303.75 & 192.14 & 160.61 & 136.68 \\
\hline
\end{tabular}

Table-7: Fracture Energy from Size Effect Method \& RILEM Work Of Fracture Method

\begin{tabular}{|l|l|l|l|}
\hline \multirow{2}{*}{ Beam Series } & \multicolumn{2}{|l|}{ Mean prediction of fracture energy $\left(\mathrm{N}-\mathrm{m} / \mathrm{m}^{2}\right)$} & \multirow{2}{*}{ Ratio of $\left(\mathrm{G}_{\mathrm{F}} / \mathrm{G}_{\mathrm{f}}\right)$} \\
\cline { 2 - 3 } & Size Effect Method $\left(\mathrm{G}_{\mathrm{f}}\right)$ & $\begin{array}{l}\text { RILEM Work-of- } \\
\text { fracture Method }\left(\mathrm{G}_{\mathrm{F}}\right)\end{array}$ & Ran \\
\hline Series A & 59.17 & 131.93 & 2.23 \\
\hline Series B & 49.11 & 107.16 & 2.18 \\
\hline Series C & 43.5 & 85.95 & 1.98 \\
\hline
\end{tabular}




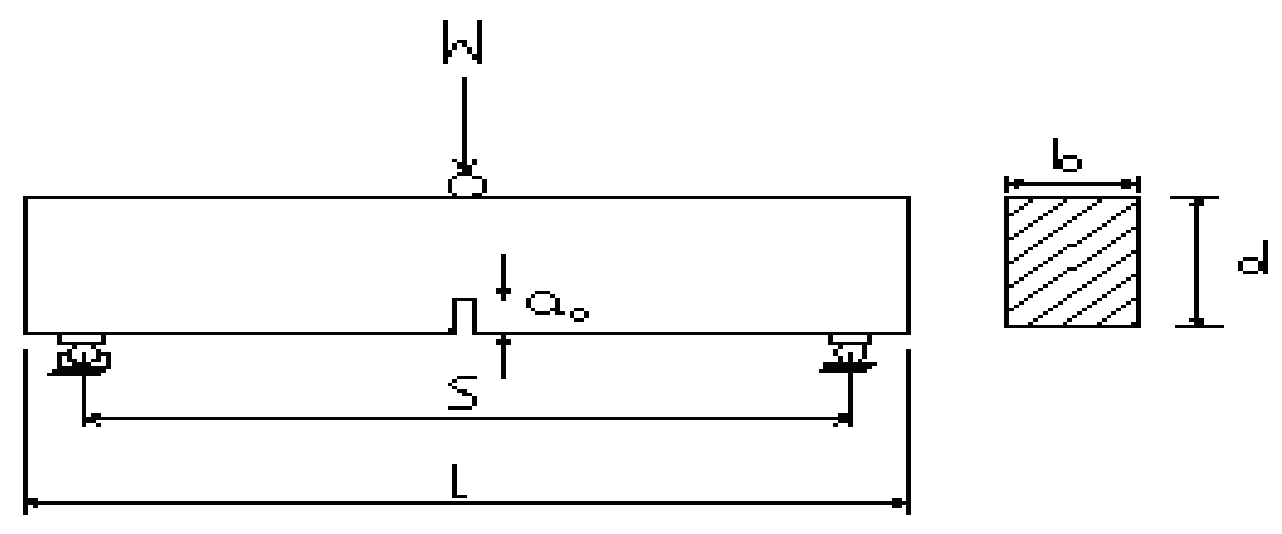

Fig-1: Typical three point bending test set up

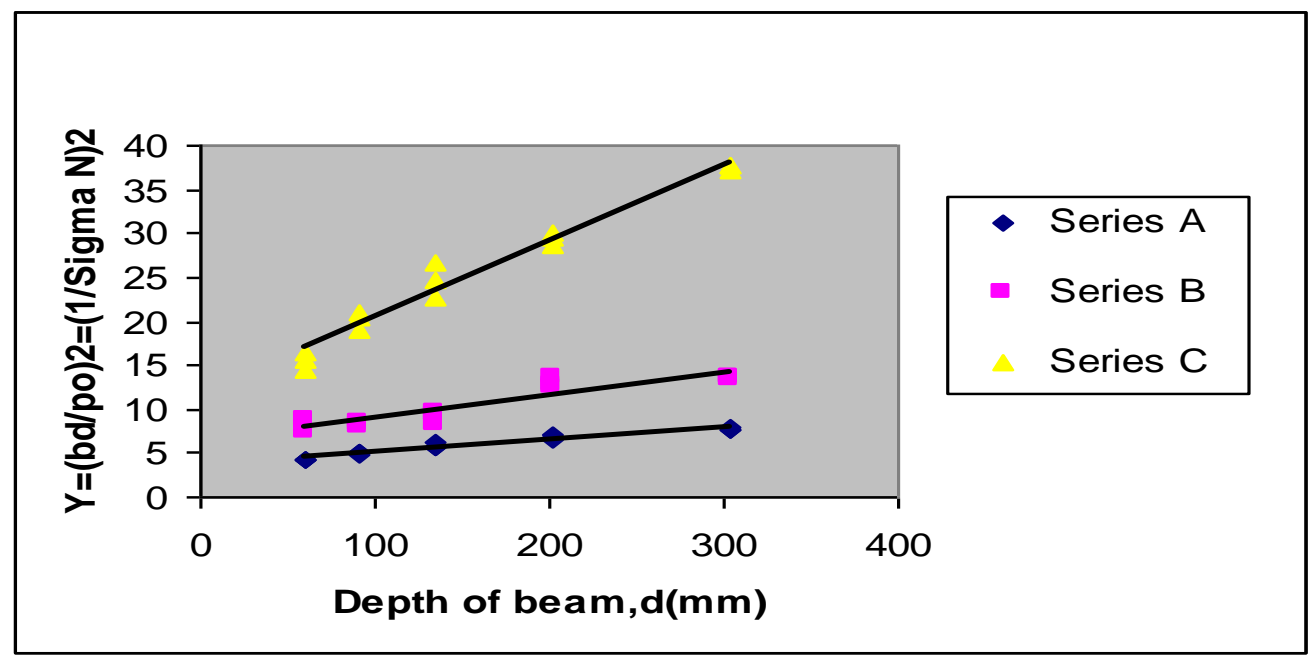

Fig-2: Linear Regression Graphs for Series A, Series B, Series C Beams

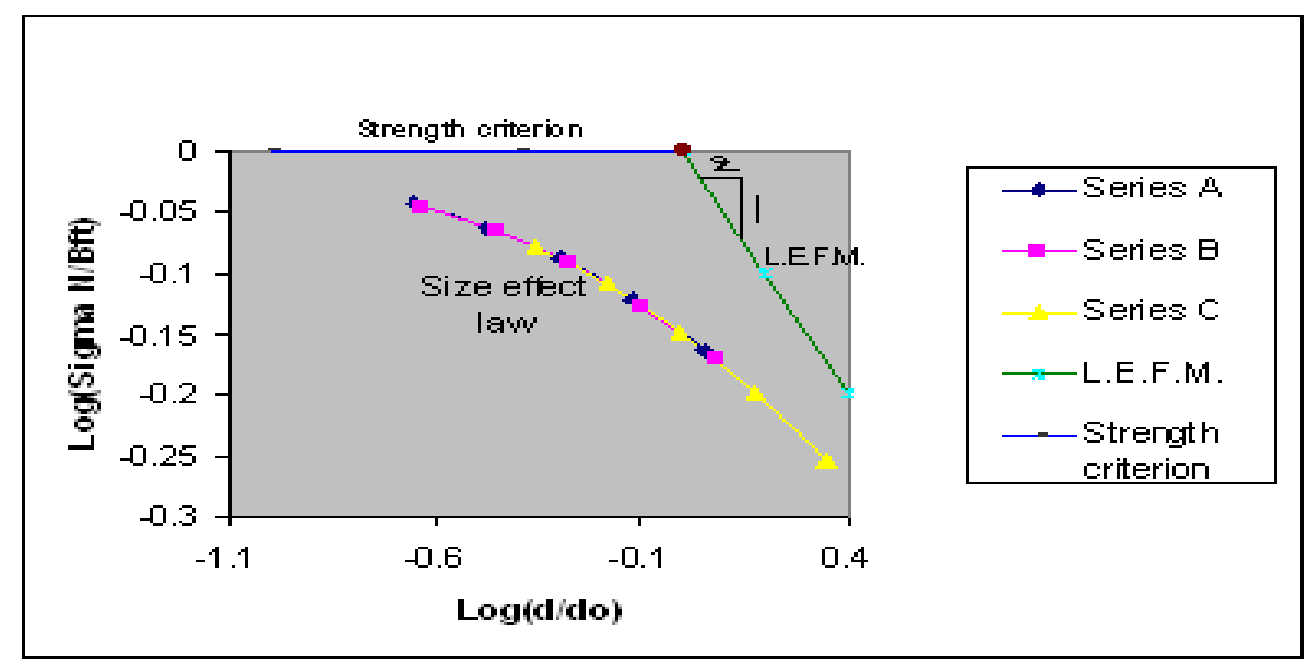

Fig-3: Size effect law graph for Series A, Series B, Series C Beams 


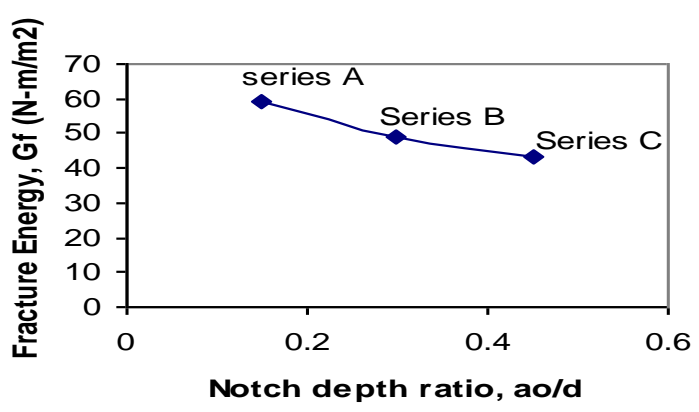

Fig-4: Fracture energy (Mean prediction) variation with Notch depth ratio (ao/d)

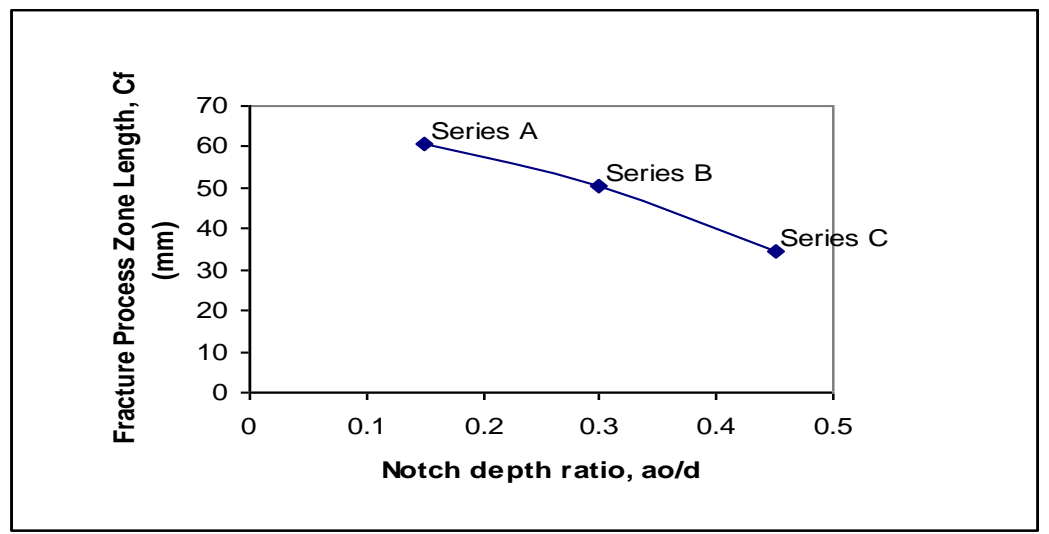

Fig-5: Effective length of Fracture process zone variation with Notch depth ratio (a/d)

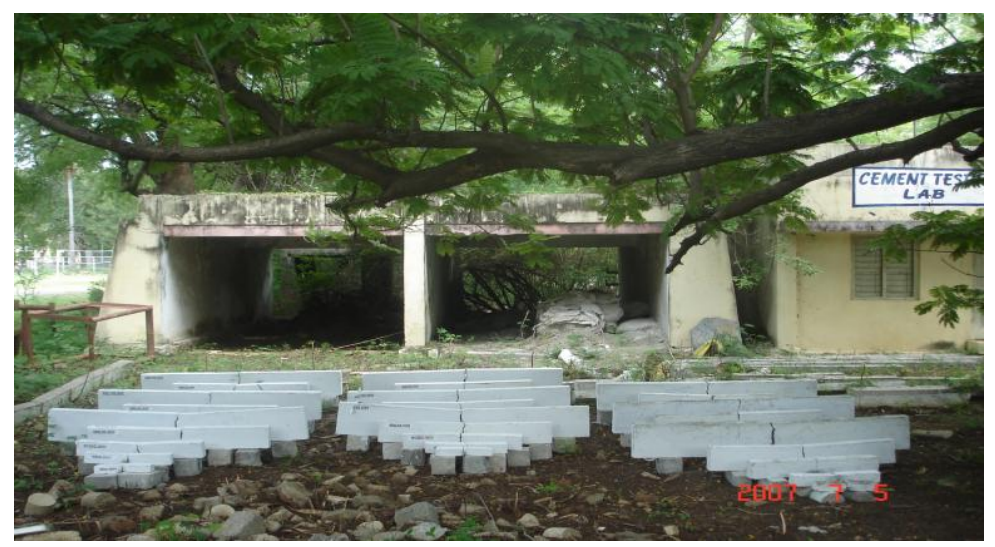

Fig-6: Tested beams Series A, Series B, Series C 